\title{
Promotion of critical thinking in e-learning: a qualitative study on the experiences of instructors and students
}

This article was published in the following Dove Press journal:

Advances in Medical Education and Practice

5 May 2016

Number of times this article has been viewed

\author{
Mitra Gharib' \\ Mitra Zolfaghari² \\ Rita Mojtahedzadeh' \\ Aeen Mohammadi' \\ Atoosa Gharib ${ }^{3}$ \\ 'E-learning in Medical Education \\ Department, Virtual School, Tehran \\ University of Medical Sciences, \\ ${ }^{2} \mathrm{E}$-learning in Medical Education \\ Department, Virtual School, Nursing \\ and Midwifery Care Research Center, \\ Tehran University of Medical Sciences, \\ ${ }^{3}$ Pathology Department, School of \\ Medicine, Shahid Beheshti University \\ of Medical Sciences, Tehran, Iran
}

Correspondence: Mitra Gharib

E-learning in Medical Education

Department, Virtual School, Tehran

University of Medical Sciences, Dolatshahi

All, Naderi St, Keshavarz BLVD,

I4I66|474|,Tehran, Iran

Tel +982I 88966486

Email gharibmi@sina.tums.ac.ir
Background: With the increasing popularity of e-learning programs, educational stakeholders are attempting to promote critical thinking in the virtual education system. This study aimed to explore the experiences of both the instructors and the students about critical thinking promotion within the virtual education system.

Methods: This qualitative study recruited the instructors and students from four academic disciplines provided by the Virtual School of Tehran University of Medical Sciences (Tehran, Iran). All programs were master's degree programs and utilized a blended (combination of e-learning and face to face) training. Semistructured interviews with the participants were used to collect data.

Results: The participants had a variety of experiences about how to promote critical thinking. These experiences were conceptualized in four main themes, namely, instructional design, educational leadership and management, local evidence, and belief systems.

Conclusion: The present study clarified the factors affecting critical thinking promotion in e-learning. Not only the instructors but also the educational designers and leaders can benefit from our findings to improve the quality of virtual education programs and promote critical thinking.

Keywords: thinking, distance education, graduate education, learning, framework

\section{Background}

Higher education generally aims to promote active learning experiences in students. Higher education institutes traditionally applied a variety of approaches to provide face-to-face training. Although this type of education has never been static, recent technological advances have increased interest in virtual education. ${ }^{1}$ Following the revolutionary changes that resulted from modern technologies during the 21 st century, greater numbers of students tend to benefit from e-learning every day. ${ }^{2}$ With growing demand for virtual courses, Tehran University of Medical Sciences (TUMS, Tehran, Iran) has admitted students for e-learning programs. However, due to the novelty of such programs in Iran, educational planners are concerned about the establishment and implementation of an evidence-based education in accordance with e-learning standards.

During the early stages of online learning development, the focus was primarily on familiarization of the instructors with technology; now, e-learning specialists seek to enhance innovative approaches, redefining the process of learning. ${ }^{3-5}$

Consequent to the information explosion and the introduction of various communication technologies, the attention of the educators has shifted from transfer of knowledge to knowledge building and management. Therefore, the long-term solution
Dovepress

http://dx.doi.org// 0.2147/AMEP.S10522
Advances in Medical Education and Practice 2016:7 27I-279 
is to create an educational environment in which the students can acquire the methods of learning. This will actually change the focus of education to the promotion of critical thinking and lifelong learning skills. ${ }^{6}$

Many definitions have been proposed for critical thinking. One of the most comprehensive definitions is presented by The American Philosophical Association. This association defines critical thinking as follows:

Purposeful, self-regulatory judgment which results in interpretation, analysis, evaluation, and inference, as well as explanation of the evidential, conceptual, methodological, criteriological, or contextual considerations upon which that judgment is based. ${ }^{7}$

Critical thinking ability is a necessity in successful e-learning, that is, virtual learners should either be critical thinkers or obtain the required skills during their education. ${ }^{3}$ Critical thinking in learning has also been underscored by the World Federation of Medical Education. It has thus been included in the world standards of medical education and is a criterion for accreditation of medical schools. ${ }^{8}$

Based on the Comprehensive Assessment Code of TUMS, virtual school graduates should be monitored for critical thinking skills. The results of our students' critical thinking skills score upon admission revealed that greater attention is required to promote critical thinking in the newly established virtual education system.

In order to find an evidence-based model to promote critical thinking, we reviewed the preceding researches. In fact, numerous qualitative and quantitative studies have addressed critical thinking in face-to-face environment. Some quantitative researches have assessed critical thinking by questionnaire..$^{9-11}$ In the same way, quantitative methods were used to evaluate the effects of various teaching methods on critical thinking. ${ }^{12,13}$ On the other hand, qualitative studies have addressed the process of critical thinking and proposed models for its promotion. ${ }^{14-17}$ To the best of our knowledge, limited researches have concentrated on critical thinking in virtual education in medical science field. Previous qualitative and quantitative researches in virtual education showed the effectiveness of teaching approaches such as discussion board, focus group, and problem-based and task-based strategies on the promotion of critical thinking. ${ }^{18-22}$ However, a comprehensive research that could address how to promote critical thinking in virtual learning environment has not been conducted so far. Furthermore, we noticed that some cultural dimensions and instructor-student interactions in our virtual education system could not be elaborated through quantitative methods. So, we conducted this grounded theory approach in order to design a framework for enhancing critical thinking in our virtual environment.

\section{Methods}

This grounded theory approach used in-depth semistructured interviews with open-ended questions to collect data.

\section{Setting}

This study was conducted at the Virtual School of TUMS. This school offers advanced academic degrees on a blended format, that is, Internet based with a minimum of two face-to-face blocks; final examinations are paper based and performed in the campus. The programs are presented asynchronous. At the time of this study, our school offers Master of Science degree in four majors, including E-learning in Medical Sciences, Medical Education, Medical Library and Information Sciences, and Pharmaceutical Quality Assurance. The offered programs are approved by the Ministry of Health and Education and their curriculum is completely similar to the traditional face-to-face education. In the same way, entrance exams are similar to the traditional face-toface system; although students must possess basic computer literacy skills upon admission.

\section{Study population}

The study population comprised all faculty members $(n=38)$ and students $(n=63)$ of School of Virtual Education of TUMS during the academic years 2011-2012, 2012-2013, and 2013-2014. It is noteworthy that some students attending "E-learning in Medical Sciences" and "Medical Education" programs were faculty members themselves. Hence, the student population in our study included a special range of individuals who have teaching experiences.

We used purposive sampling in our study; faculty members were selected based on their work experience in e-teaching, educational background, and school assessment results. Students were selected based on their educational background, grade point average, and interest in e-learning. To collect the data, semistructured interviews were conducted until data saturation. After analyzing the first 22 subjects (12 faculty members and ten students), no new theme emerged. To ensure data saturation, we conducted nine more interviews (with four faculty members and five students); 
these interviews added no new insights and we concluded that data saturation level was reached.

\section{Data collection}

After acquiring the necessary permissions from the Virtual School of TUMS authorities, the subjects were explained about the nature and objectives of the study, the voluntariness of participation, anonymity and confidentiality of information, and their right to have access to the results. In addition, we ensured participants that they had the right to terminate the interview or even withdraw from the study at any time. We assured them that we would not use their data to evaluate their performance in any way. The participants were informed about the possible use of their direct quote in a qualitative article, but we certified that their name and other identifying information would be kept anonymous. We encouraged the participants to ask questions at any time about the nature of the study or the method used. Besides the earlier verbal explanations, we prepared an informed consent document containing adequate information concerning our research (Figure S1). All participants voluntarily agreed to participate in the study and signed the consent. Meetings were then arranged with those who consented to participate. The time and place of the interviews were determined by the subjects. The interviews were conducted individually in a peaceful and private environment. All formal interviews were recorded and transcribed verbatim immediately after completion. It is noteworthy that the recorded interviews were anonymized. In order to anonymize participants, we use abbreviation signs based on the initial two letters of their role ("In" denotes instructor and "St" denotes student) and a number indicating their interview turn.

Interviews as well as the whole process of data analysis were conducted in Persian; a professional salaried translator translated the quotes in the present article. The translation was reviewed and compared with the original Persian version by a research team member who was an expert in English.

\section{Data analysis}

A grounded theory approach using open, axial, and selective coding was used to analyze the data.

Two authors independently extracted and coded the key thoughts, ideas, and comments based on our research questions. The extracted codes were discussed among authors regularly. A list of codes was developed and new codes were added to the list. The list of codes and examples of relevant quotation were discussed with the wider research team until agreement was achieved. The codes with similar concepts were merged to identify the major categories. Relevant categories were then combined. Then the core category was selected and other categories were systematically connected to it to identify themes. In addition, each code was also compared with all other codes using constant comparative analysis. After comparing the coded data and overlapping themes, the initial data were coded and the next interview was coded accordingly. In other words, data items were first compared with each other and then with the developing theory. Reminder notes (including ideas and relationships) were also taken from the beginning of the study to facilitate qualitative data analysis. Eventually, no new codes were extracted after analyzing the 22nd interview. At this point, 69 codes were extracted and combined to form 12 categories and, eventually, four themes. To ensure data saturation, nine new interviews were independently coded by a third researcher. As no new themes emerged from these interviews, we considered that saturation was reached.

In order to ensure the relevance of data interpretations to the studied phenomenon, the participants were asked to confirm the obtained codes. In addition, external observers were requested to review the interviews, codes, and reminders. Furthermore, collecting data from both faculty members and students, who were involved in the system, increased the acceptability and confirmability of the collected data.

\section{Results}

A total of 31 individuals, including 16 instructors (six female and ten male; mean age: $48.5 \pm 7.96$ years) and 15 students (nine female and six male; mean age: $37.33 \pm 4.68$ years) were interviewed. Four main themes, that is, instructional design, educational leadership and management, local evidence, and belief systems, were found to describe critical thinking promotion in virtual education (Table 1). The four themes and their categories and sample quotes from the participants are described in the following sections. Quotes have been coded as follows: [In] denotes instructor and $[\mathrm{St}]$ denotes student.

\section{Instructional design}

Our participants believed that effective instructional design, that is, defining an appropriate philosophical outlook and theoretical framework, developing proper learning management system (LMS) software (Vestasoft Company, Tehran, Iran), and designing the virtual teaching-learning process (including the subthemes of course objectives and expected outcomes, problem-based teaching strategies in the virtual system, and outcome-based assessment), were indispensable to the promotion of critical thinking. 
Table I Main themes and categories associated with promotion of critical thinking in virtual education

\begin{tabular}{|c|c|c|}
\hline \multirow[t]{2}{*}{$\begin{array}{l}\text { Instructional } \\
\text { design }\end{array}$} & \multicolumn{2}{|c|}{$\begin{array}{l}\text { Philosophical outlook and theoretical framework } \\
\text { Learning management system }\end{array}$} \\
\hline & $\begin{array}{l}\text { Virtual teaching-learning } \\
\text { process }\end{array}$ & $\begin{array}{l}\text { Course objectives } \\
\text { and outcome-based } \\
\text { assessment } \\
\text { Problem-based teaching } \\
\text { strategies } \\
\text { Feedback }\end{array}$ \\
\hline Educational & \multicolumn{2}{|l|}{ Meritocracy } \\
\hline leadership and & \multicolumn{2}{|c|}{ Empowering the instructors } \\
\hline management & \multicolumn{2}{|c|}{ Support system for virtual environment } \\
\hline Local evidence & \multicolumn{2}{|c|}{ Thinking within the academic framework } \\
\hline Belief systems & \multicolumn{2}{|c|}{ Sociocultural roots of thinking } \\
\hline & \multicolumn{2}{|c|}{$\begin{array}{l}\text { Personal characteristics and differences of the } \\
\text { instructors }\end{array}$} \\
\hline & \multicolumn{2}{|c|}{$\begin{array}{l}\text { Personal characteristics and differences of the } \\
\text { students }\end{array}$} \\
\hline
\end{tabular}

The subjects highlighted the substantial role of adopting a humanistic philosophy and learner-centered learning environment design with minimal teacher-student hierarchy in the promotion of critical thinking.

[...] What is very important in the virtual environment is teacher-students interactions and relationships [...]. [In]

We found the features of the LMS software to have considerable effects on designing a thought-provoking environment.

In our system, the students interact primarily with their instructors. I think that brainstorming would be needed if we want to examine different aspects of a problem using critical thinking [...]. [St]

On the other hand, the participants underlined the effects of the teaching-learning design on the promotion of critical thinking. If acquiring critical thinking skills is not asserted as a course objective, neither the instructors nor the students will feel compelled to work toward it.

The learners should know that they want and need to acquire it. The instructors should also know that it has to be taught along with other elements [...] it should be incorporated in assessment systems for both learners and instructors. [In]

Our participants also pointed to the role of teaching strategies. They believed that the use of various teaching methods, limiting the amount of content and with proper content preparation would be effective on the promotion of critical thinking.
The amount of content is also important. If you have too much to study, you'll never get a chance to think [...]. [St]

Since the assignments and feedbacks played the most important role in our system, the subjects suggested that analytical assignments, attention to creativity, providing proper feedback on assignments, and making answers available to other students could all be beneficial to critical thinking promotion.

Feedbacks provided on assignments highlight the learning cycle of the subject $[\ldots]$. [St]

\section{Educational leadership and management}

According to the experiences of our participants, the promotion of critical thinking entailed the collaboration and support of educational managers in developing a meritocracy, empowering the instructors and creating a support system for virtual learning.

The subjects suggested that critical thinking skills and attitudes of both instructors and students had to be evaluated before recruitment.

I think a pretest is missing. The test that assessed us didn't

assess our critical thinking skills. [St]

Empowerment of the faculty members can also have a role in promotion of critical thinking. Providing workshops and educational courses on critical thinking can thus be highly effective.

It probably wasn't even very clear for them (the teachers) to want to guide us [...]. [St]

Moreover, developing an efficient support system for virtual learning, such as electronic library services and access to various resources, could facilitate the critical thinking process.

Conditions conducive to learning, for example, availability

of electronic resources, should be provided [...]. [St]

\section{Local evidence}

The category of local evidence comprised two subcategories of thinking within academic discipline framework and evidence-based education.

Our participants perceived virtual education as a new and unfamiliar experience. Local studies are, therefore, required to facilitate the promotion of critical thinking in Iranian e-learners.

It was my first experience as an e-teacher. It was both interesting and challenging. Just like the attitude in evidence-based medicine, we should look for various evidences [...]. [In] 
Our findings also showed that critical thinking development depended on environmental conditions, educational content, and academic discipline.

I'm not sure if it's possible to separate thinking from the content per se. But it doesn't mean that where there is content, there is thinking or critical thinking. Content can be provided without evoking any thoughts [...]. [In]

\section{Belief systems}

The participants expressed that people's beliefs about the world and themselves generally affect their critical thinking. Factors in this category were intensely dependent upon the participants' personal characteristics and beliefs. This theme consisted of four subthemes, namely, sociocultural roots of thinking, people's previous experiences and intellectual backgrounds, the instructors' personal characteristics and differences, and the students' personal characteristics and differences.

The subtheme of sociocultural roots of thinking indicated that the emergence and development of critical thinking required a thought-provoking sociocultural context.

[...] a sense of insecurity to express our thoughts. Social roots that can encourage or inhibit thinking in general and specifically critical thinking. Humans are social creatures; and learning and thinking are social phenomena and they are not far from social conditions. [In]

The subtheme of people's previous experiences and intellectual backgrounds suggested that the formation of critical thinking is a gradual process that begins in childhood and gradually evolves during school and university years (Figure 1).

When the stereotypes are so strong, it is very difficult to change them [...]. It may not happen consciously, sometimes it is just in your subconscious [...]. [In]

The participants also highlighted the significance of the instructors' attitude; instructors cannot teach without taking their own personal values and interests into account. They, consciously or unconsciously, believe in a particular teaching philosophy, which affects their teaching process. The instructors' self-awareness about their accepted philosophy and values plays an essential role in critical thinking education.

It's all about the teaching philosophies adopted by the instructors; whether they want to have people that criticize, or people that memorize [...]. [In]

The subtheme of personal characteristics and differences of the learners reflects another dimension of critical

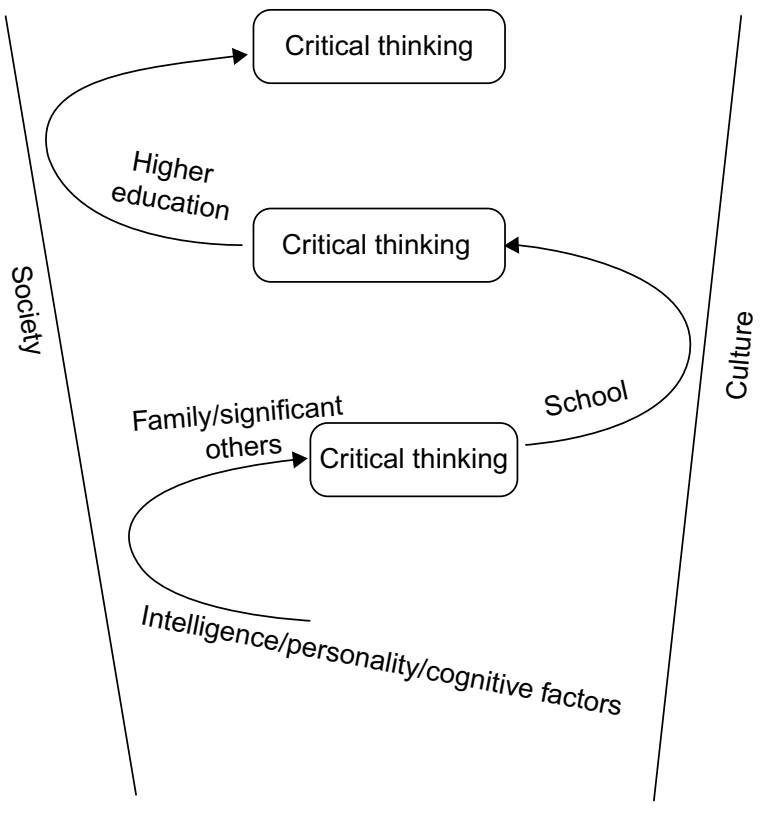

Figure I The spiral development of critical thinking.

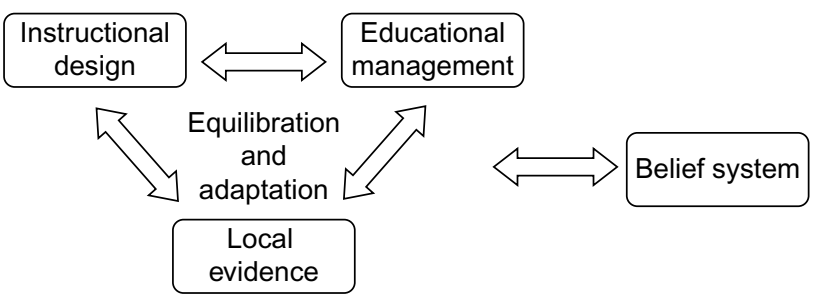

Figure 2 Framework of promoting critical thinking in e-learning.

thinking. The participants perceived deviation from norms as a prominent characteristic of e-learners that could facilitate critical thinking. Furthermore, according to participants' experiences, self-directed, introvert, self-sufficient, and fieldindependent learners with read/write or assimilating learning style preferences could perform more successfully in virtual education and critical thinking.

I guess people that turn to virtual learning are somehow critical of the existing atmosphere. Virtual education is not common in our current society; it isn't actually the norm in education [...]. [In]

\section{Discussion}

Our findings revealed several interrelated factors that affected critical thinking development. Our participants perceived virtual education, particularly the teaching and learning of critical thinking, as a new and unfamiliar experience which led to a sort of imbalance. Therefore, a framework, with adaptation and finding equilibrium as the core, was proposed (Figure 2). 
It is noteworthy that our findings, as in other qualitative researches, may be context dependent and in the continuing discussion, we will focus on our local implementation; meanwhile, we have described our research context in a way that faculty members, educational designers, and leaders in other settings can transfer these findings to their own context. Furthermore, we tried to meet a "conceptual generality" in our suggested framework. We have developed our framework based on ideas; for example, the belief system component is an important concept regardless of context, yet each institution and country may possess its own culture and belief system and act upon it.

In this framework, the factors within two main themes, that is, instructional design and educational leadership and management, could be planned and manipulated to promote critical thinking in the short term; in addition, factors in the "local evidence" theme could be modified in the short and medium term. These factors were thus considered as dynamic factors in the proposed framework. Meanwhile, the factors in the belief systems theme were constant and unchangeable during virtual education. These were, therefore, regarded as static factors.

Among our findings, the instructional design had been formerly incorporated in the virtual education system of TUMS. Nevertheless, redesign based on the findings of the present study was also scheduled.

Our participants highlighted the necessity of a philosophical and theoretical framework in course development. While e-learning is recognized as the pioneer of change in higher education, it needs to be justified. The main question is the nature of the learning experience and the desired educational outcomes. ${ }^{6}$ Educational strategies and an appropriate studentcentered atmosphere play a determining role in the promotion of critical thinking. ${ }^{23}$

While our virtual programs had been developed based on a combination of cognitivism and constructivism, after exploration of the participants' experiences, course outlines and faculty empowerment workshops were revised to comply with humanistic strategies and student-centered education requirements. Moreover, the school's educational council approved of integrating the promotion of critical thinking in the general objectives and assessment of courses.

Our participants appreciate the presence of face-to-face sessions, limited number of students, and asynchronous approach in our system as factors encouraging critical thinking. These findings showed that the planning of our system was in line with the standards on virtual education. In fact, e-learning had to be complemented with face-to-face classrooms to facilitate the achievement of educational goals; in addition, higher numbers of virtual students $(>20)$ can reduce student-instructor interactions. ${ }^{5}$ Meanwhile, asynchronous online group discussions could be more successful than in-person discussions in promoting critical thinking. ${ }^{18}$

Generally, e-learning systems entail critical thinking. However, such systems should be closely monitored to prevent the mere transfer of information and ensure interactive techniques. ${ }^{24}$ Constant feedback provision by the instructors and obliging the students to solve problems and make rational decisions were effective in teaching critical thinking; the promotion of in-depth learning and critical thinking in virtual learners depended on the given assignments, available time, instructors' guidance, and provided resources. ${ }^{25}$ According to Sendag and Odabasi, ${ }^{26}$ the problem-based learning strategy could significantly improve critical thinking skills in e-learners. Our findings regarding the importance of applying diversified teaching methods to promote critical thinking were comparable with previous researches done in traditional face-to-face environment. ${ }^{12-14}$

Our students pointed to the large volume of educational materials as a barrier to critical thinking. This was exactly in line with the previous research on virtual education. Reasonable volume of materials are, therefore, recommended. ${ }^{3}$ Interestingly, in contrast to the students, the instructors did not mention the volume of materials as a barrier. Instead, they considered the course nature (the possibility of discussing and judging different options) more influential.

All the aforementioned experiences were discussed and confirmed in empowerment workshops for the instructors and students. A content production unit was also established in the school to facilitate the provision of richer content and multimedia subjects by offering proper consultation to the instructors.

In addition, the features of our LMS were also found to prevent critical thinking. Since only student-teacher interactions were allowed in the existing system, the need for revising the LMS and creating greater interaction opportunities was felt. Several studies have emphasized the role of LMS design and interactions in the promotion of critical thinking in virtual education. ${ }^{27,28}$ Although interactions between the students were not possible in the first version of the LMS software, upgrading the software during this study provided the possibility of communication between students. A third version of the software will also be released soon.

Based on our findings in the educational leadership and management theme, we planned for virtual students support services and a fully equipped online library, which was 
finally launched in 2014. In this regard, paying attention to critical thinking skills in faculty and student recruitment, empowerment of the existing instructors through educational workshops, and providing sabbaticals were considered and planned.

The current study revealed the importance of local evidence in promoting critical thinking. Due to the substantial effects of basic knowledge on critical thinking, critical thinking processes should be modified in different academic disciplines. ${ }^{29}$ Moreover, critical thinking is a field-dependent phenomenon, which is affected by sociocultural and educational factors. ${ }^{30}$ As a result, our school has developed and implemented a number of strategies, including the establishment of qualitative and quantitative research projects in various fields. Although the results of these projects may not be accessible in the short term, they will facilitate reliable and evidence-based planning in the future.

The significance of belief systems in critical thinking development was highlighted by many studies. ${ }^{31-34}$ People's beliefs relate to their already established memory, which is formed by the significant others within the family and the community and is developed over time. Any new issue is carefully compared with the existing cache and is then analyzed. ${ }^{11}$ As a result, when postgraduate students enter the course, their formed thoughts and judgments are extremely difficult to change. Our participants believed that individuals who register in virtual courses tend to possess personal characteristics and beliefs that are conducive to critical thinking. Deviation from norms, which was suggested as an important personal characteristic by our participants, has been rarely mentioned in previous research. Therefore, given the cultural contexts, further study is warranted to clarify its roles.

The belief system and personal characteristics of the instructors are also important. Since the instructors may act as role models, their characteristics, such as accepting criticism, knowledge, and skills, can affect the promotion of critical thinking. Hence, efforts to promote critical thinking should begin long before entry to the course. Furthermore, certain characteristics of both virtual instructors and students should be taken into consideration upon their recruitment.

Similar to our findings, education professionals believe that a virtual instructor is, in fact, a facilitator who should accept criticism and be honest, flexible, responsive, well mannered, and persevering. On the other hand, critical thinking skills of virtual learners will depend upon their ability to work independently and deal with educational materials with minimal intervention of the instructor. ${ }^{3}$

\section{Conclusion}

This study provided a useful insight into the experiences of e-learners and e-teachers about the promotion of critical thinking. Virtual degree courses, especially in medical sciences, are a novel phenomenon in Iran that requires research-based scientific foundations to develop. The results and frameworks suggested in this study can act as an appropriate model for the promotion of critical thinking in virtual education. Our findings clarified the factors facilitating and inhibiting critical thinking. We also underscored the important role of educational design and management in directing opportunities and eliminating threats in virtual disciplines. Attention to the experiences of instructors and students about virtual education can help educational designers and instructors in developing more effective virtual courses.

\section{Acknowledgment}

This research was supported by Tehran University of Medical Sciences and Health Services grant no 12728-76-01-90.

\section{Author contributions}

All authors contributed toward data analysis, drafting and critically revising the paper and agree to be accountable for all aspects of the work.

\section{Disclosure}

The authors report no conflicts of interest in this work.

\section{References}

1. Hamilton J, Tee S. Smart utilization of tertiary instructional modes. Comp Educ. 2010;54(4):1036-1053.

2. Van de Vord R. Distance students and online research: Promoting information literacy through media literacy. Internet High Educ. 2010;13(3):170-175.

3. Palloff R, Pratt K. The Virtual Student. San Francisco: Jossey-Bass; 2003.

4. Rosenberg M. Beyond E-learning. San Francisco: Pfeiffer; 2006.

5. Horton W. E-learning by Design. San Francisco: Pfeiffer; 2011.

6. Garrison DR, Anderson T. E-learning in the 21st Century. London: Routledge Falmer; 2004.

7. American Philosophical Association. National Panel of Experts. Critical Thinking: A Statement of Expert Consensus for Purposes of Educational Assessment and Instruction. The Delphi Report. Millbrae: The California Academic Press; 1990.

8. World Federation for Medical Education. Basic Medical Education, WFME Global Standards for Quality Improvement. Denmark, University of Copenhagen: WFME Office; 2012.

9. Boso CM, Gross JJ. Nurse educators' perceptions of critical thinking in developing countries: Ghana as a case study. Adv Med Educ Pract. 2015;4(6):555-560.

10. Gharib M, Rabieian M, Salsali M, et al. Critical thinking skills and critical thinking dispositions in freshmen and senior students of Health Care Management. Ir J Med Educ. 2009;9(2):125-135. Persian. 
11. Miller D. Longitudinal assessment of critical thinking in pharmacy students. Am J Pharmaceut Educ. 2003;67(4):890-897.

12. Qing Z, Ni S, Hong T. Developing critical thinking disposition by taskbased learning in chemistry experiment teaching. Proc Social Behav Sci. 2010;2(2):4561-4570.

13. Broadbear J, Keyser B. An approach to teaching for critical thinking in health education. J Sch Health. 2000;70(8):322-330.

14. Hassan Poor M. Critical Thinking Process in Nursing Education $[\mathrm{PhD}$ thesis]. Tehran: Iran University of Medical Sciences; 2008. Persian.

15. Myrick F, Yonge O. Enhancing critical thinking in the preceptorship experience in nursing education. $J$ Adv Nurs. 2004;45(4):371-380.

16. Varga L. Exploring Critical-Care Nurses' Perceptions About Critical Thinking [MSc thesis]. Ontario: Brock University; 2007.

17. Borglin G, Fagerström C. Nursing students' understanding of critical thinking and appraisal and academic writing: a descriptive, qualitative study. Nurse Educ Pract. 2012;12(6):356-360.

18. Guiller J, Durndell A, Ross A. Peer interaction and critical thinking: Face to face or online discussion? Learn Instruct. 2008;18(2):187-200.

19. Richardson J, Ice P. Investigating students' level of critical thinking across instructional strategies in online discussions. Internet High Educ. 2010;13(1-20):52-59.

20. De Leng BA, Dolmans DHJM, Jöbsis R, Muijtjens AMM, Van Der Vleuten CPM. Exploration of an e-learning model to foster critical thinking on basic science concepts during work placement. Comp Educ. 2009;53(1):1-13.

21. Pucer P, Trobec I, Žvanut B. An information communication technology based approach for the acquisition of critical thinking skills. Nurse Educ Today. 2014;34(6):964-970.

22. Parker S, Mayner L, Michael Gillham D. E-learning for critical thinking: Using nominal focus group method to inform software content and design. Nurs Midwifery Stud. 2015;4(4):e30471.
23. Simpson E, Courtney M. Critical thinking in nursing education: a literature review. Int J Nurs Pract. 2002;8(2):89-98.

24. Staib S. Teaching and measuring critical thinking. J Nurs Educ. 2003;42(11):498-508.

25. Harasym PH, Tsai TC, Hemmati P. Current trends in developing medical students' critical thinking abilities. Kaohsiung $J$ Med Sci. 2008;24(7):341-355.

26. Şendağ S, Odabaşı HF. Effects of an online problem based learning course on content knowledge acquisition and critical thinking skills. Comp Educ. 2009;53(1):132-141.

27. Ransdell S, Gaillard-Kenny S. Blended learning environments, active participation, and student success. Int $J$ Allied Health Sci Pract. 2009;7(1):1-4.

28. Weller M. Virtual Learning Environment. London: Routledge; 2007.

29. Meyers Ch. Teaching Students to Think Critically. Michigan: JosseyBass; 1986.

30. Hendricks J. Preparing Students for Critical Thinking Applications on Standardized Tests [PhD thesis]. Minneapolis: Walden University; 2010.

31. Hergenhan BR, Olson MH. An Introduction to Theories of Learning. Virginia: Pearson Prentice Hall; 2004.

32. Jarvis P. Adult Education and Lifelong Learning: Theory and Practice. New York: Routledge; 2010.

33. criticalthinking.org [homepage on the Internet]. Critical thinking in every domain of knowledge and belief [updated July 23, 2007; cited September 6, 2007]. Available from: http://www.criticalthinking. org/page.cfm?PageID=698\&CategoryID=68. Accessed August 9, 2014.

34. cognitivebehavior.com [homepage on the Internet]. Belief system [updated November 3, 2013; cited December 1, 2013]. Available from: http://www.cognitivebehavior.com/theory/beliefsystems.html. Accessed July $24,2015$. 


\section{Supplementary material}

Thank you for agreeing to participate in this study. This study intends to design a framework for enhancing critical thinking in virtual disciplines. Your participation consists of an interview lasting $\sim 1$ hour. You will be asked a series of questions about your experiences of critical thinking promotion in e-learning system of TUMS. If additional follow-up/clarification were needed, you will be contacted by phone.

The interview will be tape recorded for later analysis. Participation is voluntary and you have the right to terminate the interview or even withdraw from the study at any time. All records will be kept confidential in the secure possession of the researcher. The data you will provide are not to be used to evaluate your performance in any way. Results will be available to you upon request.

You are encouraged to ask questions or raise concerns at any time about the nature of study or the method used.

Insights gathered by you and other participants will be used in writing a qualitative article. Though direct quotes from you may be used in the paper, your name and other identifying information will be kept anonymous.

By signing this consent form, I certify that I have read and agreed to participate in this study.

Signature of interviewee

Date signed

Figure SI Informed consent form

Advances in Medical Education and Practice

\section{Publish your work in this journal}

Advances in Medical Education and Practice is an international, peerreviewed, open access journal that aims to present and publish research on Medical Education covering medical, dental, nursing and allied health care professional education. The journal covers undergraduate education, postgraduate training and continuing medical education

\section{Dovepress}

including emerging trends and innovative models linking education, research, and health care services. The manuscript management system is completely online and includes a very quick and fair peer-review system. Visit http://www.dovepress.com/testimonials.php to read real quotes from published authors.

Submit your manuscript here: http://www.dovepress.com/advances-in-medical-education-and-practice-journal 